\title{
Time Decay of Pulse Current in Capillary Glow Discharge
}

\author{
Muayad A. Ahmed ${ }^{1 *}$, Aasim A. Azooz ${ }^{2}$ \\ ${ }^{1 *}$ Department of Physics, College of Education for Pure Science, University of Mosul, Mosul, Iraq \\ ${ }^{2}$ Department of Physics, College of Science, University of Mosul, Mosul, Iraq \\ E-mail: ${ }^{1 *}$ moyadalharbi@yahoo.com, ${ }^{2} \underline{\text { aasimazooz1@yahoo.com }}$
}

(Received December 02, 2019; Accepted January 20, 2020; Available online September 01, 2020)

DOI: 10.33899/edusj.2020.126339.1032, () 2020, College of Education for Pure Science, University of Mosul.

This is an open access article under the CC BY 4.0 license (http://creativecommons.org/licenses/by/4.0/).

\begin{abstract}
:
A high voltage pulse generator was development and implemented. This generator has the capacity to generate a sequence of pulses with a varying pulse height from 0 to $5 \mathrm{kV}$, and changes the pulse width in ms range. This generator has been tested and used to study the pulse glow discharge in argon by using the capillary tube under pressure 0.3 to 0.5 torr. This study has succeeded to establish the nature of discharge relaxation (plasma relaxation) when a high voltage pulse causes a breakdown in the gas (converts to conducting case).The current decays when the obtained voltage pulse is switched off. The electronic switching is a successful tool which can be used to generate high voltage pulses with flexibility that help to adjust an adjustable peak height voltage pulse, pulse duration and pulse width. The plasma returns to a neutral status when the current decay time is less than plasma relaxation time. This mean that if plasma decays time is more than relaxation time the plasma will transit from pulse glow discharge to continuous discharge. In this study the current- voltage characteristics in relation to different gas pressures were in the abnormal glow discharge regime.
\end{abstract}

Keywords: Plasma, pulse discharge, time decay, glow discharge.

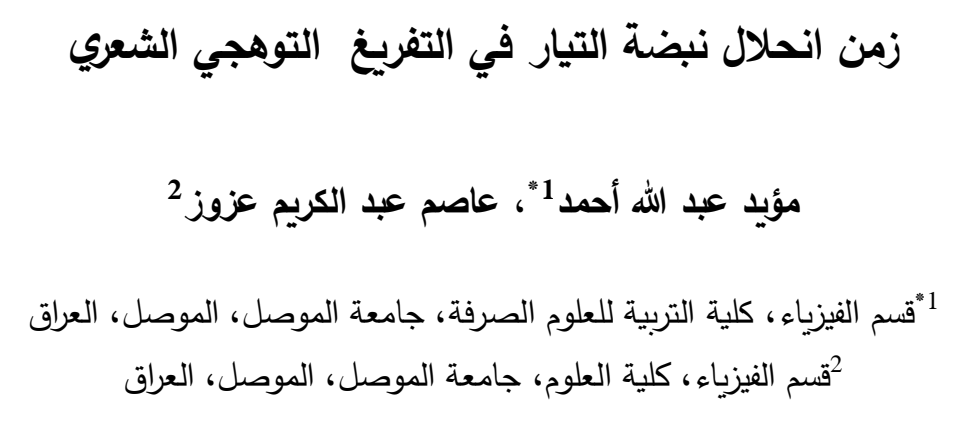

الخلاصة

تم تطوير و تنفيذ مولد نبضي بفولتية عالية. المولد النبضي له القدرة على أن يولد نبضات متتالية مع تغيير ارتفاع النبضة من صفر

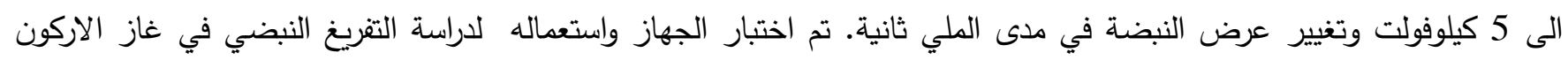
باستخدام الانبوب الثعري تحت ضغط واطئ 0.3 to 0.5 torr. تلك الدراسة است لطبيعة استرخاء التثريخ الكهربائي ( استرخاء 


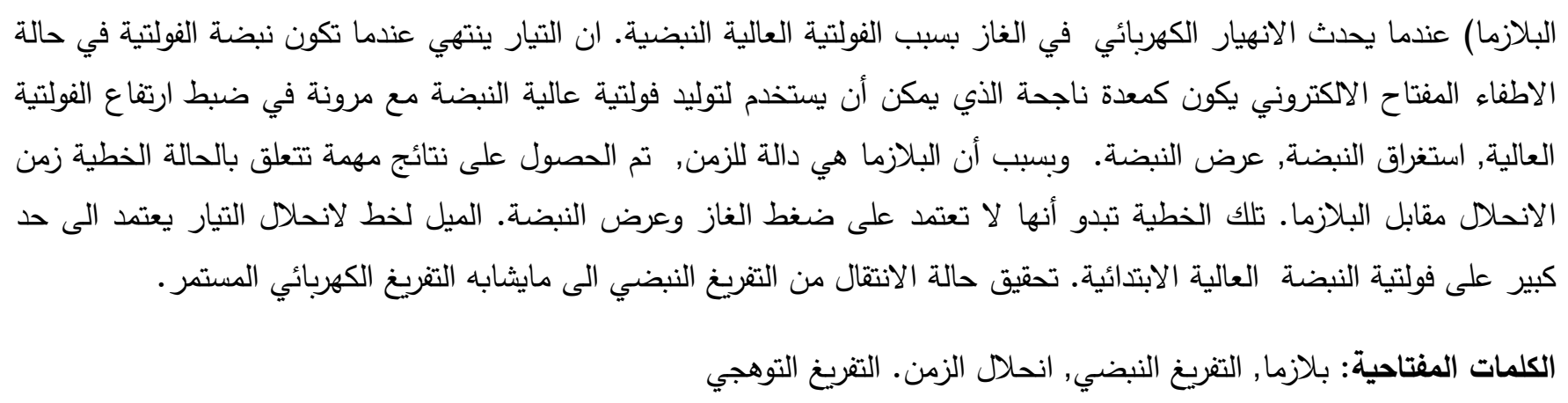

\section{Introduction}

Electrical discharge in gases is a phenomenon, which appears when a neutral gas becomes as a conductor. This means that the gas becomes electrically conductor which contains free charges ions and electrons. There are many types of discharges as DC, alternating discharge: radio frequency one with frequency $13.56 \mathrm{MHz}$ microwave plasma[1, 2]. In addition to application of radio frequency voltage to a glow discharge a discrete pulses of voltage of milliseconds -microseconds can also be applied. The ionization, excitation of plasma are related to field strength in a non-linear pattern leading to more instantaneous sputtering, excitation and ionization of the glow discharge, which improves the sensitivities in spectrochemistry[1]. The pulse discharge can be produced by superimposing the DC voltage, a function which can be achieved by using some electrical circuits [3].

The hollow cathode is very important in plasma discharge as it is used to avoid striation in plasma [4]. The hollow cathode is used for various applications in high current pulse discharge as in closing switches situations [5]. The measurements show that at low pressure the effect of the geometry shape of the hollow cathode is strong when the effect of Townsend ionization [6]. The hollow cathode in pulse discharge usually allows high current densities without heating the cathode [7]. The enlarged emission from the hollow cathode due to the secondary electron emission by photon metastable excited atoms, in addition to the increased ionization because of the cavities [7]. The hollow cathode can take many geometric shapes and if the outer surface of hollow cathode is insulated, then the negative glow could lie within the cathode. This process of hollow cathode will affect the hollow cathode characteristics such as, sustaining, electron and ion current densities [8]. The commonest geometries of the hollow cathode used in plasma discharge are cylinders; therefore, a high density of the discharge is achieved by using hollow cathode $[8,9$, and 10$]$.

Bogaert and his colleagues tried to explain the behavioral features of various plasma species so they designed a new modeling network for a millisecond pulsed glow discharge using argon gas supplemented copper $(\mathrm{Cu})$ cathode [11]. In 2012 Nayan and his colleagues designed a high voltage pulse generator using the integrated circuit 555 as astable multivibrator connected to car ignition coil. They used this generator in dielectric barrier discharge in atmospheric pressure to study the effect of plasma in surface treatment especially in alteration of roughness on the surfaces used in their study [12]. Other research deal with audio frequency $(100-10000 \mathrm{~Hz})$ discharge in argon and data that show significant changes in the discharge current waveform with frequency. These changes seem to be associated with the glow discharge profile and color [13].

\section{Experimental setup}

The work was conducted in two stages. The first stage developed and operation of high voltage pulse generator (HVPG) while the second stage of this work included the construction of the discharge tube.

The circuit of HVPG was divided into several parts; each part was designed to perform a particular function. The first part of HVPG is the low voltage pulse generator, which is also the first part of the 555 
integrated circuit that has been connected as an astable multivibrator. This circuit can be operated safely from power supply as high as $(+15$ volt $)$. This circuit usually generates successive sequence pulses with pulse height range from 0 to 15 volt. This generator has the ability to change time of the pulse and the time between two successive pulses which are changed by a potentiometer $R_{a}$ and $R_{b}$ with $C_{1}(R C)$, as shown in figure (1). Upon changing these two times in the pulse $T_{L}, T_{W}$ the total time $T$ will be changed naturally. The time $T_{W}$ is calculated by $R_{b}$ and $C_{1}$ as in equation(1).

The time of pulse width $T_{L}$ and the discharge time duration $T_{W}$ is computed by some components of the astable - multivibrator circuit as in figure (1). The two times $T_{L}, T_{W}$ is given by:

$$
\begin{aligned}
& T_{L}=0.693\left(R_{a}+R_{b}\right) C_{1} \\
& T_{W}=0.693\left(R_{b}\right) C_{1}
\end{aligned}
$$

The total time represents the summation of the two times and is given by:

$$
T=T_{L}+T_{W}=0.693\left(R_{a}+2 R_{b}\right) C_{1}
$$

The second part of HVPG is the voltage $\operatorname{divider} R_{1}, R_{2}$. The resistor $R_{1}$ represents the series dropping resistor and $R_{2}$ is the bleeder resistor. The third part is the switch transistor $T_{r 1}$ (BC107). The fourth part of the circuit in high voltage pulse generator is the Darlington pair (The compound amplifier). This component consists of two transistors T2 and T3, as it is shown in figure (1). Transistor $T_{2}$ (2N2222) is that of type (npn) while transistor $T_{3}(2 \mathrm{~N} 3055)$ represents a power transistor type (npn). This circuit is used to give high current gain, which is due to a fact that the current gain of this amplifier is the result of the multiplication between the gains of the two transistors. The two collectors of these transistors are connected together.

The commutating diode $D_{2}$ or freewheeling diode has two functions: the first one is to avoid the reversal of load voltage, while the second function is to move the load current away from the main half rectifier. 


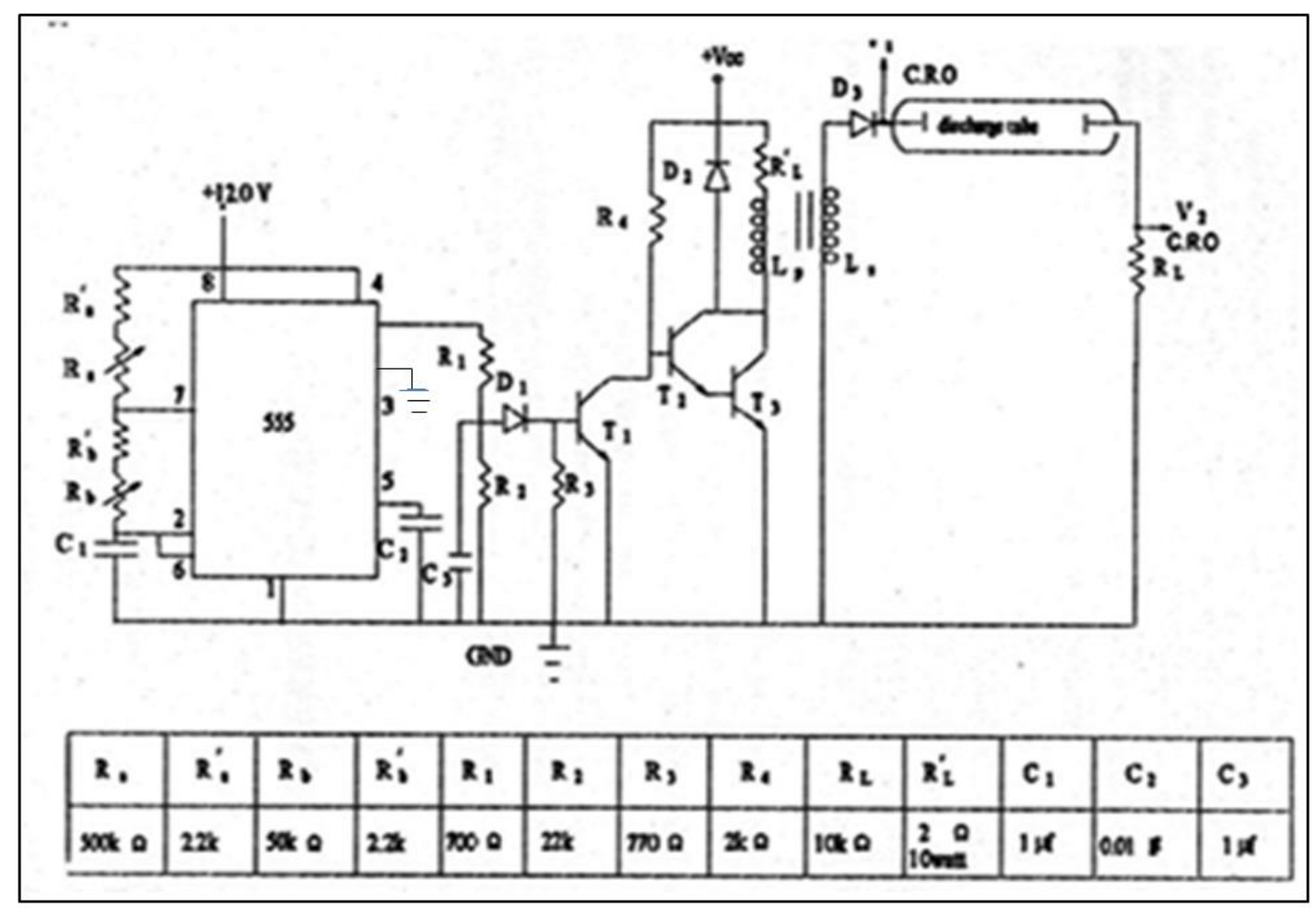

Figure (1) schematic diagram of a high voltage pulse circuit

Diode $D_{3}$ represents a high voltage diode used to permit one half of pulse to operate on the plasma while the other has a negligible effect. The last part is the transformer (Ruhmkorff coil transformer). It gives a high voltage and works under low voltage pulse, as it is shown in figure (1). The high voltage pulse power supply provides a variable pulse peak of up to $5 \mathrm{kV}$ with total current of about $20 \mathrm{~mA}$ and the length of the pulse (total time) lies from 4.5 to $420 \mathrm{~ms}$ ranges. The time interval between two successive pulses can be changed from 1.5 to $36 \mathrm{~ms}$. The pulse width can also be changed from 3 to $384 m s$.

The values that are mentioned here in this study, computed from the equations $1,2,3$. The second stage of this work represents the construction of $0.1 \mathrm{~mm}$ diameter Pyrex that is made by using plasma capillary tube with $10 \mathrm{~cm}$ in length, as it is shown in figure(2). One end of this $0.1 \mathrm{~mm}$ capillary tube is connected to a Pyrex tube $(2 \mathrm{~cm}$ in diameter $x 10 \mathrm{~cm}$ in length). At this binding site a moveable anode was added. The inter electrode distance between the two electrodes used in this work was $1.5 \mathrm{~cm}$. The anode was constructed from a (chromium-nickel) alloy wire with $0.0275 \mathrm{~cm}$ in diameter. This anode can move by external magnet. It has a flexible motion, so it can be moved easily. This feature helps to change the distance between the two electrodes. The anode was terminated outside of the cell via a solenoid wire cooper that is ended by tungsten terminal which is confirmed to the glass envelope. The capillary tube binds with its other end to another tube $(2 \mathrm{~cm}$ diameter x $10 \mathrm{~cm}$ length); so it can help in the evacuation. The other end of the $0.1 \mathrm{~mm}$ diameter capillary tube was connected to a terminal tube ( $2 \mathrm{~cm}$ diameter $\times 10 \mathrm{~cm}$ length), which was connected to evacuation system. A cylindrical hollow cathode has been fixed there in a vertical position with respect to the anode direction. The hollow cathode was constructed from nickel material $0.78 \mathrm{~cm}$ in outer diameter, $0.77 \mathrm{~cm}$ in inner diameter and $2.8 \mathrm{~cm}$ in length. The hollow cathode was used to prevent striation effect, as shown in figure (2). This diagram shows the gas and the vacuum system. The leakage rate of the system was about 0.027 torr per 
hour measure by the means of thermocouple gauge. The gas used in the test was argon. A commercial argon gas of purity $99.99 \%$ was used. Evacuation system was performed by using the mechanical pump. The system evacuated to pressure 20 micron, measured by thermocouple gauge. The degassing produce for the discharge tube was carried out by means of a high current through the tube for about six hours, with continual evacuation for the discharge tube. The pressure is measured by Edwards pirani 14 has a range $10^{-3}$ code NO. DO35-36-000 made in England. The voltage and current pulses are measured using $100 \mathrm{MHz}$ HAMEQ oscilloscope the voltage in required calculation (model HM 1004-3), which has a triggered digital voltage display facility. The pictures of the voltage and the current pulses were captured by Tektronix C-53 oscilloscope camera roll film back made by USA. The current signal appears on the oscilloscope screen across resistor $10 \mathrm{~K} \Omega$, which was connected in series with plasma. The current was measured from the occurrence of breakdown in gas. The photographed of the voltage and the current pulses were captured from oscilloscope screen.

The main aim of this study was to establish the nature of discharge relaxation when a voltage pulse causes a breakdown in the plasma. It is of great importance to find an answer to the following question: how the current can be decayed when the voltage pulse is switched off? This information can lead to a better understanding of the relaxation process that includes electron-ion recombination, ambipolar diffusion and surface effect.

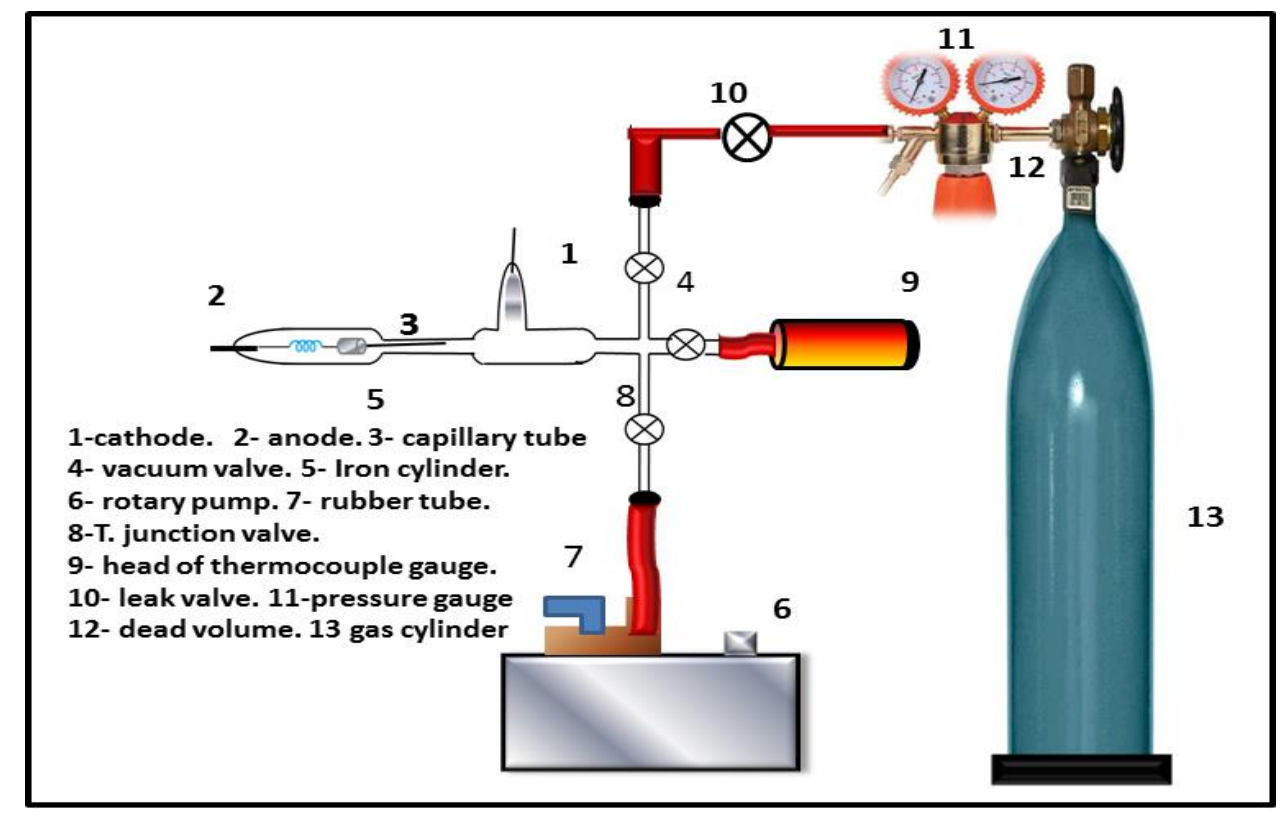

Figure (2) experimental setup

\section{Results and discussion}

High Voltage pulse, which is applied across the two electrodes, is shown in the figure (1). Figure (3) gives the relation of the discharge current against time decay as a function of $T_{W}$ at each value of pressure. Figure (4) shows the relation of the discharge current vs. time decay as a function of pressure at constant $T_{W}$. The current decay time, current and voltage values were obtained from the oscilloscope photographed screen as in figure (5). According to these photographs, it becomes very clear that after the initial high voltage pulse applied, the current starts to decay with time. The current decay seems to follow a straight line as a first approximation. The slope of the current decay line is very much 
dependent upon the initial voltage pulse. As the voltage pulse becomes high the slope tends to decrease; this serves as a powerful tool to calculate the plasma relaxation and the optimal condition for obtaining stable discharge. Post application of a low voltage pulse as in figure (5a), the plasma relaxation time will be larger than current time decay so plasma returns to neutral state i.e. the discharge stills pulsating. Upon increasing the discharge current reaching the condition shown in figure (5e), in which the plasma relaxation time becomes smaller than the current decay time this will allow glow discharge to continue until the next pulse arrives, this will create the stable condition. The development of this condition can be seen in the photographs of figure (5).
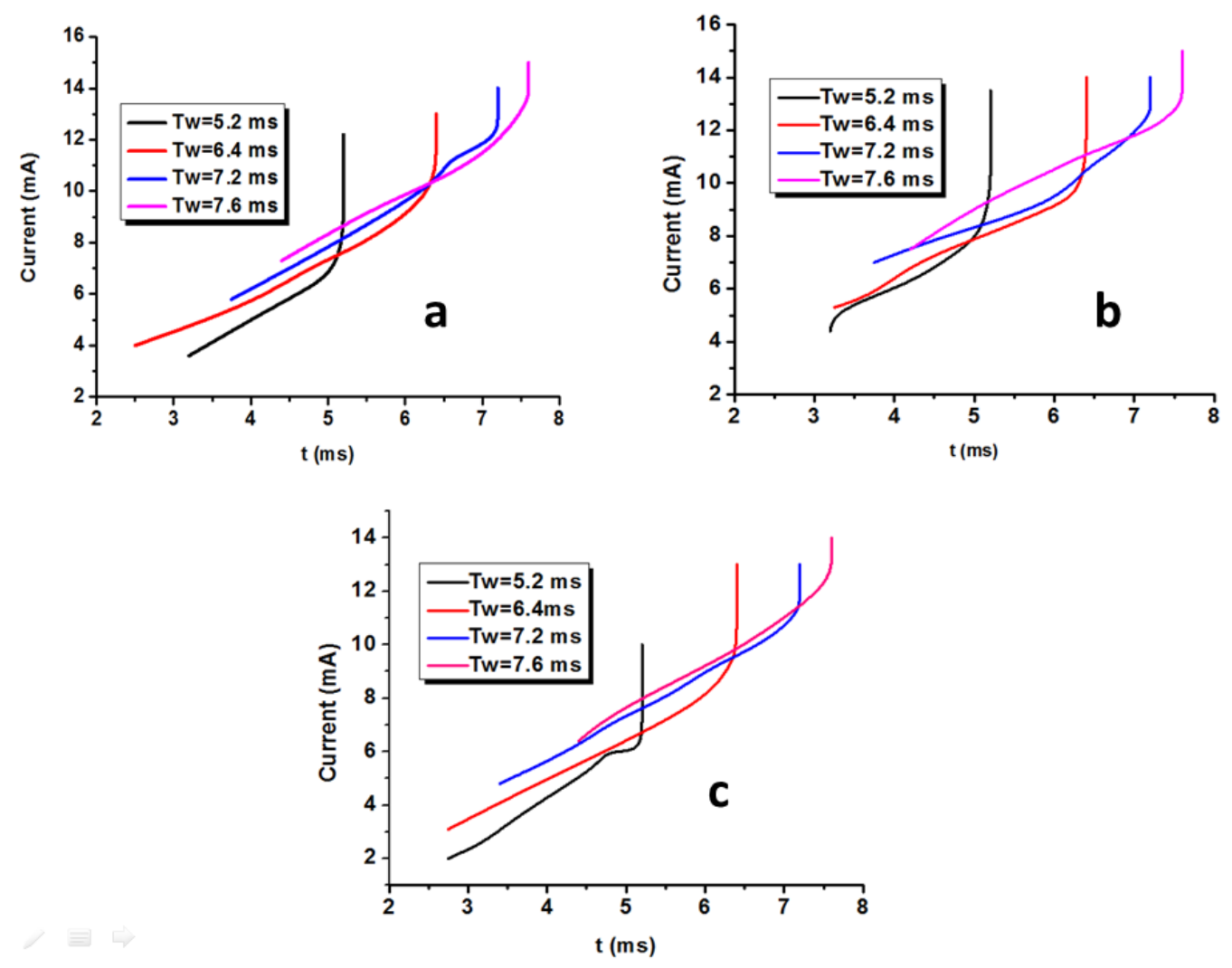

Figure(3) shows the discharge current against the time decay at inter electrodes distance $1.5 \mathrm{~cm}$ at different $T_{W}$ values. 

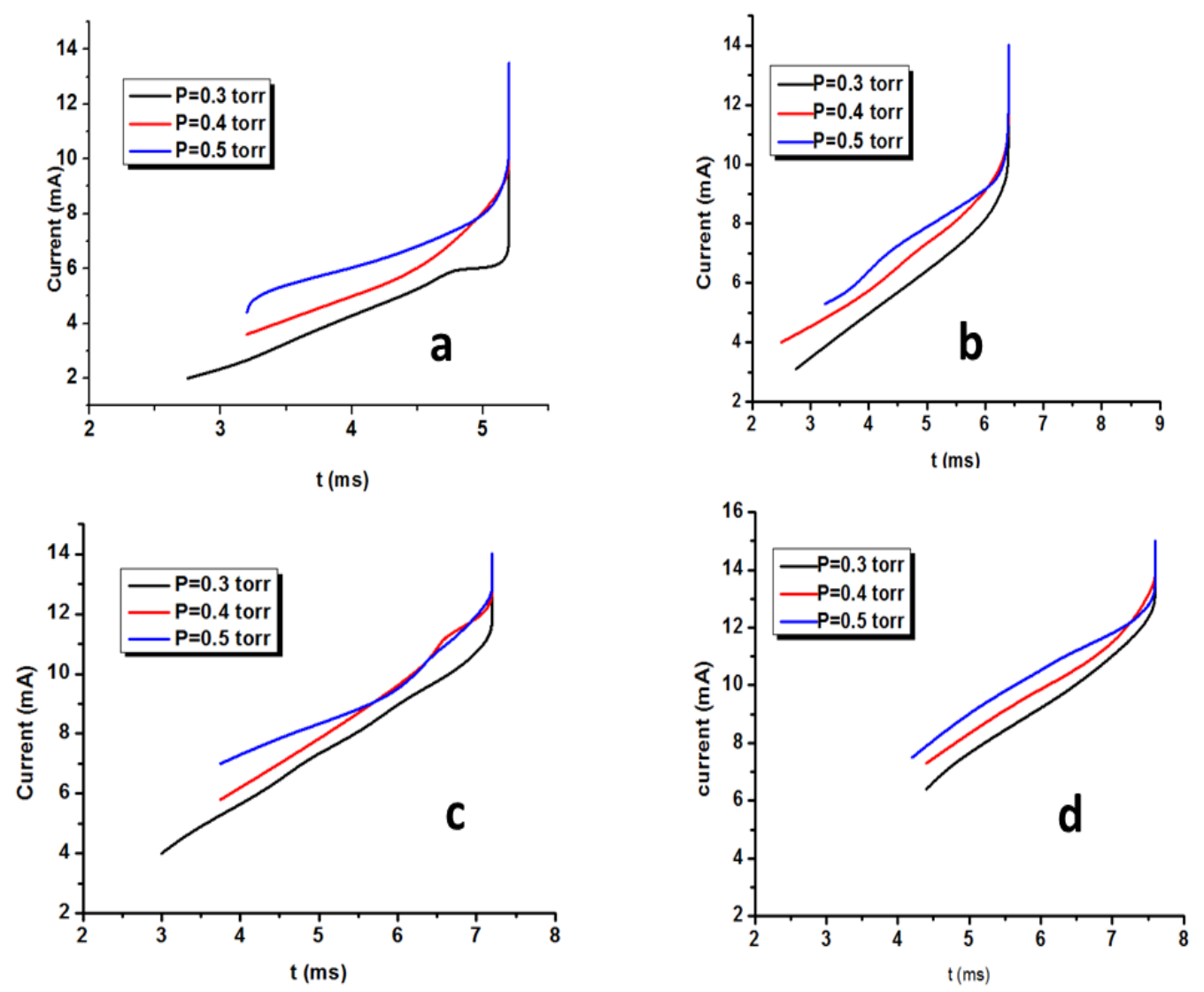

Figure (4) shows the discharge current against the decay time with inter electrodes distance $1.5 \mathrm{~cm}$ at different pressure values.

The shape of voltage pulse is a spike, as it shown in figure (5a), and the exponentially decreases with time is not smooth but is an oscillation. This oscillation may be due to the influence of some items in the circuit, as $R L C$ in the circuit diagram. The $R L C$ is composed of $\mathrm{R}, \mathrm{L}$ and $\mathrm{C}$. $\mathrm{R}$ in our circuits is a resistance, which is in series with discharge tube. $L$ represents the inductance of the secondary winding, while $\mathrm{C}$ includes three components, which are the effect of coil winding capacitance, output capacitance and stray winding capacitance to ground. Each RLC circuit has differential equation. The differential equation of the network has a solution in the form $p(S t)$; this leads to find roots $(S)$ of characteristic equation; the roots are given by:

$$
S=-\frac{1}{2 R_{L} C} \pm\left[\left(\frac{1}{2 R_{L} C}\right)^{2}-\frac{1}{L_{S} C}\right]^{1 / 2} \ldots \ldots \ldots \ldots
$$

If $\eta$ represents the damping constant, the under damping is defined by:

$$
\eta=\frac{1}{2 R_{L}} \sqrt{\frac{L_{S}}{C}}
$$

The shape of the decay pulse can be explained by the damping factor as will be given: when $\eta=0$, we see the roots are purely imaginary, when $\eta=1$, the roots are equal the case will be a critical damping, then we have: 


$$
\frac{V_{0}}{A}=\frac{4}{L_{S}} R_{L} t e^{-2 R_{L} t / L_{S}}
$$

Where $V_{0}$ and $A$ are the output voltage and amplitude of high voltage pulse respectively. Now, when $\eta>1$ there is no oscillation in the output, and the response is said to be over damp.

$$
\frac{V_{0}}{A}=R_{L} t e^{-R_{L} t / L_{S}}
$$

When $\eta<1$, the output voltage will be a sinusoid whose amplitude decays with the time, and the response is said to be under damped $[14,15]$ :

$$
\frac{V_{0}}{A}=\frac{2 \eta}{\sqrt{1-\eta^{2}}} e^{-2 \pi \eta t} / 2 \pi \sqrt{L_{s} C} \quad \sin 2 \pi \sqrt{1-\eta^{2}} \frac{t}{2 \pi \sqrt{L_{S} C}}
$$

Figures (3 and 4) explain the relation between different $T_{W}$ at constant pressure and different pressure values at constant $T_{W}$ respectively.

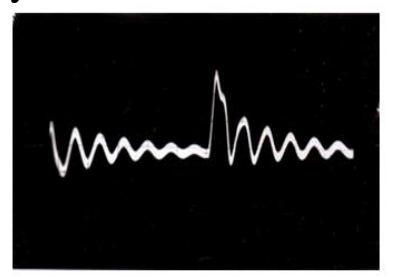

a
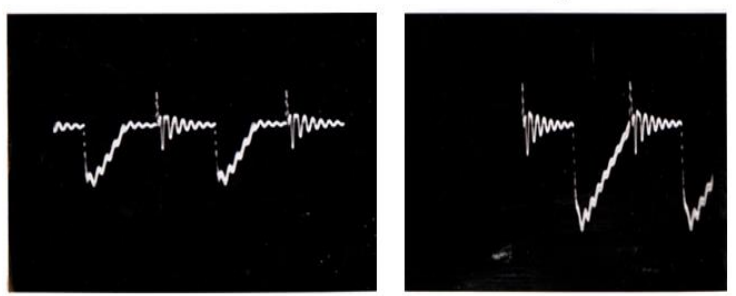

C

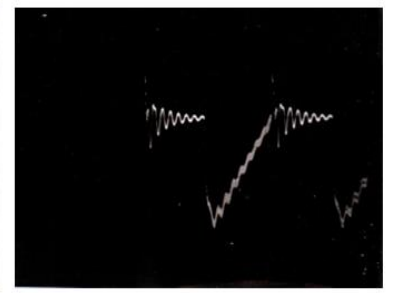

b

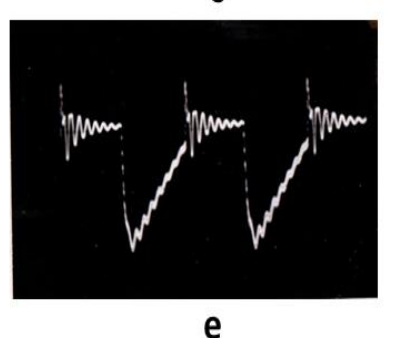

d

Figure(5) manifests (or you can say 'shows') the voltage and current pulses photographs, (a) spike voltage pulse shape b, c, d and e represent the pulse current pictures and give the stages of the time growth of pulse glow discharge current at pressure 0.3 torr the inter electrodes distance is $1.5 \mathrm{~cm}$ and $T_{W}=5.2 \mathrm{~ms}$. 
The plasma discharge arises by applying sufficient high voltage that leads to breakdown in gases. Figure (6) is given I-V characteristics for argon discharge in different pressure values at inter electrodes distances $\mathrm{d}=1.5 \mathrm{~cm}$ and $T_{W}=5.8 \mathrm{~ms}$. The result indicates a systematic increase in the discharge current with voltage applied is related to abnormal glow discharge regime. This case denotes that the discharge in right side from Paschen curve. The abnormal cathode fall occurs when negative glow covers the cathode, this increases the current [16].

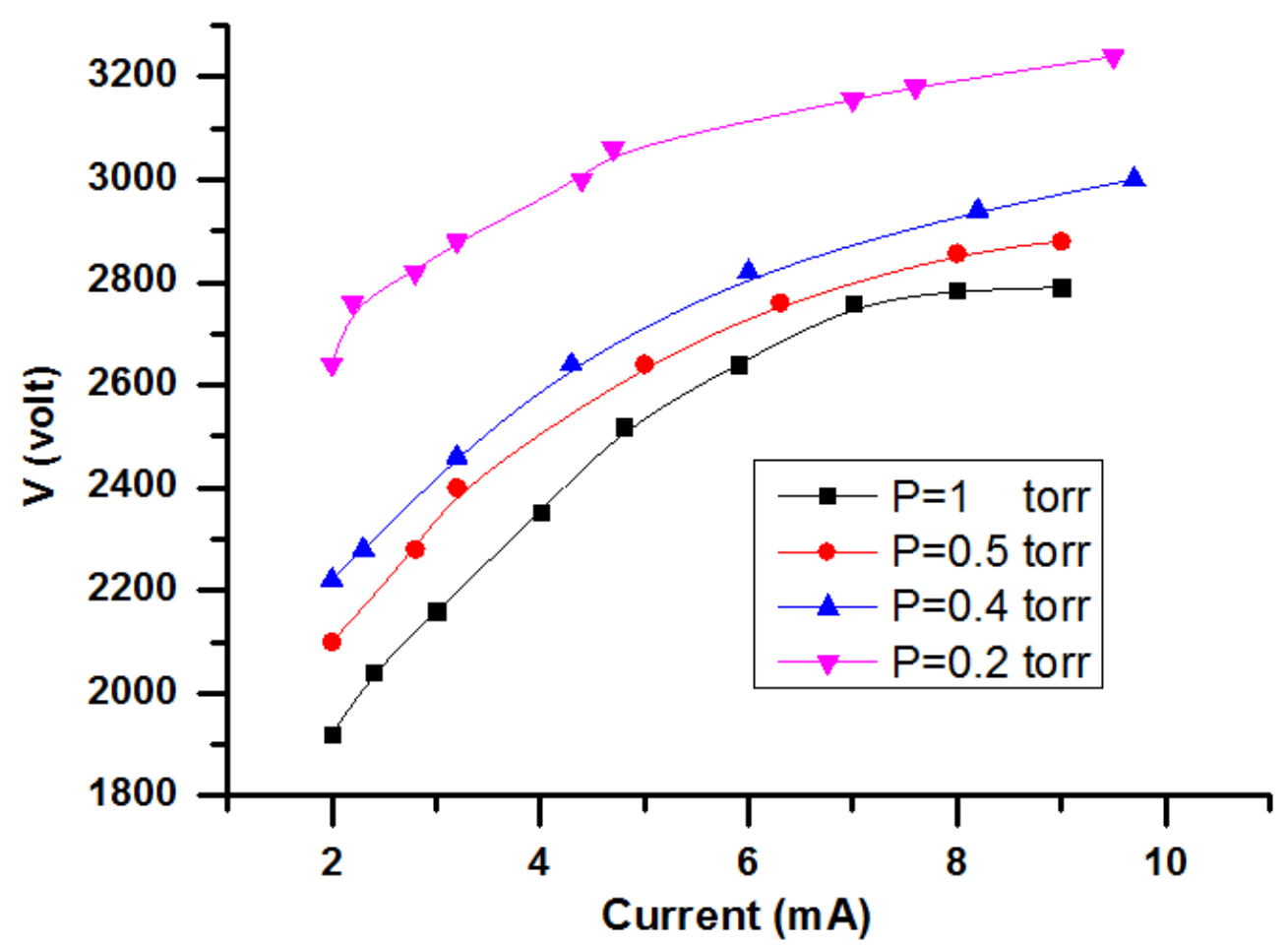

Figure (6) shows I-V characteristics for argon discharge in different pressure values at $\mathrm{d}=1.5 \mathrm{~cm}$ $\operatorname{and} T_{W}=5.8 \mathrm{~ms}$.

\section{Conclusions}

The developed high voltage power supply enabled the variation in pulse time, total time and pulse voltage height. The transition from pulse glow discharge to continuous discharge was achieved. The I-V characteristics occurred in the abnormal glow discharge regime.

\section{Acknowledgment}

I would like to acknowledge all who provide a help to complete this work. I would like to express my deep appreciation to the head and staff of the department of physics for their constant help. I would also like to thank the head of the department of physics, college of science university of Mosul. I sincerely thank my supervisor professor Aasim Abdulkareem Azooz for his constant help, guidance and encouragement to achieve this work. 


\section{References}

1- Bogaerts, A., Neyts, E., Gijbels, R., \& Van der Mullen, J., Spectrochimica Acta Part B: Atomic Spectroscopy, 57(4), 609-658 (2002) .

2- Azooz, A. A., and M. A. Ahmad., Plasma Science and Technology 15, 9:881(2013).

3- Nayan, N., Zahariman, M. R., Ahmad, M. F. B., Ali, R. A. M., Sahdan, M. Z., \& Hashim, U., (2012) September. Electronics (ICSE) pp. 596-599 (2012).

4- Awsi, S. K., Am. J. Mod. Phys., 2:276-81(2013).

5- Sozer, E. B., Koppisetty, K., \& Kirkici, H. (2007, June). (2007) 16th IEEE International Pulsed Power Conference (Vol. 1, pp. 133-135) (2007) IEEE.

6- Favre, M., Lenero, A. M., Choi, P., Chuaqui, H., \& Wyndham, E., Applied physics letters, 60, 1: 32 34 (1992).

7 - Schaefer, G., \& Schoenbach, K. H., In Physics and Applications of Pseudosparks pp. 55-76 (1990). Springer, Boston, MA.

8- Radu, M., Journal of research of the National Bureau of Standards 89, 2:143-185 (1984).

9- Efimova, V., Hoffmann, V., \& Eckert, J., Journal of Analytical Atomic Spectrometry, 26, 4: 784-791 (2011).

10- Jackson, G. P., \& King, F. L., Spectrochimica Acta Part B: Atomic Spectroscopy, 58, 8:1417-1433 (2003).

11- Bogaerts, A., Gijbels, R., \& Jackson, G. P., Journal of Analytical Atomic Spectrometry, 18, 6:533548 (2003).

12- Higashiyama, Y., Nakajima, T., \& Sugimoto, T., Proc. 2018 Electrostatics Joint Conference $1(2018)$.

13- Azooz, A. A., and A. Y. Owaid. Chinese Physics Letters 29.10:105203 (2012).

14- Jackson, H. W., and White, P. A. "Introduction to Electric Circuits", seven edition, Prentice-Hall International Edition (1989).

15- Schilling, D. L., Charise, B., "Electronic Circuit", McGr-Hill Book Company, New York (1980).

16- Von Engel A., (1955), "Ionized Gas", $2^{\text {nd }}$ Ed Oxford University press, Oxford (1955). 